\title{
O apoio institucional como método de análise-intervenção no âmbito das políticas públicas de saúde: a experiência em um hospital geral.
}

\author{
Institutional support as a method of analysis-intervention \\ in the context of public health policies: \\ the experience in a general hospital.
}

\author{
Maria Elizabeth Barros de Barros ${ }^{1}$ \\ Carla Ribeiro Guedes ${ }^{2}$ \\ Monica Maria Raphael Roza ${ }^{2}$
}

${ }^{1}$ Departamento de Psicologia, Centro de Ciências Humanas e Sociais, Universidade Federal do Espírito Santo. Av. Fernando Ferrari s/n Goiabeiras. 29.075-041 Vitória ES.

betebarros@uol.com.br ${ }^{2}$ Universidade Federal Fluminense
Abstract The article addresses the elaboration of a method for analysis/intervention in the sphere of public health policies. It describes the introduction of the National Humanization Policy of the Unified Health System (SUS) in a general hospital. It proposes institutional support expressed as a method for doing things that seeks the creation of group action, work process analysis and involves examining work management methods. It relies on promotion of health, which implies the production of subjects. The promotion of health is a networking process that involves individuals, work processes, knowledge and power. The challenge of supporting this network is to foster the exercise of the role of individuals and summon the inherent creative potential of life for the construction of new ways of work management that are not new forms of subjection. The study aims to show that by means of institutional support it is possible to bring to the fore the forces involved in the promotion of health and thereby summon the groups for an analysis of its implications. The effects produced indicate that this is a powerful strategy for the intervention of work processes within the scope of public health policies.

Key words Public health policies, National Humanization Policy, Institutional support, Worker health
Resumo O artigo aborda a construção de um método de análise/intervenção no âmbito das políticas públicas de saúde, que se delineia de forma articulada aos princípios da Política Nacional de Humanização do SUS em um hospital geral. Apresenta o apoio institucional como um método que se expressa num modo de fazer que persegue a criação de grupalidade, a análise dos processos de trabalho e envolve a problematização dos modos de gestão. A Política Nacional de Humanização aposta na produção da saúde que implica em produção dos sujeitos. A produção da saúde é um processo em rede que envolve sujeitos, processos de trabalho, saberes e poderes. O desafio do apoio é fomentar nessa rede o exercício do protagonismo dos sujeitos e convocar o potencial criativo próprio da vida para a construção de novos modos de gerir o trabalho que não sejam novas formas de assujeitamento. $O$ estudo pretende mostrar que por meio do apoio institucional é possível colocar em cena as forças implicadas na produção de saúde e com isso convocar os grupos a uma análise de suas implicações. Os efeitos produzidos indicam que esta é uma estratégia potente para a intervenção dos processos de trabalho no âmbito das politicas públicas de saúde.

Palavras-chave Políticas públicas de saúde, Política nacional de humanização, Apoio institucional, Saúde do trabalhador 
Fomentar uma política pública com características de cogestão num país marcado pela desigualdade, cujo aparelho de Estado está a serviço das classes governantes e de interesses privados, não é uma tarefa fácil. Os que militam no campo da saúde coletiva nunca tiveram a ilusão de que o processo da reforma sanitária brasileira seria simples. Sabiam que o percurso era "longo e penoso", e que a luta não seria breve e amena ${ }^{1}$. Como contribuir, então, para que essa luta prospere?

Há cinco anos o Ministério da Saúde, com a formulação de uma Política Nacional de Humanização da Atenção e da Gestão do SUS (PNH), vem construindo práticas que demonstram preocupação com a saúde coletiva. Sua proposta é desenvolver uma política que questione o autoritarismo com o qual têm funcionado os serviços de saúde no Brasil.

O desafio se apresenta, principalmente, porque a transição de uma política de governo para uma política pública não se faz com facilidade nem está garantida: Construir políticas públicas na máquina do Estado exige todo um trabalho de conexão com as forças do coletivo, com os movimentos sociais, com as práticas concretas no cotidiano dos serviços de saúde ${ }^{2}$. Então, uma política pública só se concretiza quando "o que fazer" está em sintonia com o "como fazer". Conceitos precisam estar afinados com práticas, e conhecimento, com transformação da realidade.

Princípios, métodos, diretrizes, dispositivos; a PNH vem se dedicando à tarefa de definir novos modos de atuação na área da saúde para que não nos habituemos à fragmentação do trabalho, já bastante naturalizada hoje. No âmbito do SUS, questões como gestão participativa, lutas de poder nos serviços e a fragmentação dos processos de trabalho, também estão sendo analisadas. O objetivo é promover uma mudança radical no modelo burocrático e verticalizado que caracteriza, muitas vezes, a prática no campo da saúde. São inúmeros os desafios enfrentados, e para vencê-los a PNH escolheu um caminho no sentido espinoziano, ou seja, não está alinhada com práticas que buscam a causa da impotência como um vício da natureza humana.

Segundo Campos, a humanização formulada pela PNH é uma estratégia politica que tem funcionado 'como um dispositivo valioso', na medida em que amplia a agenda para a politica de saúde no Brasil ${ }^{3}$. O autor destaca a PNH como uma política que vai na contramão de práticas tecnocráticas e estratégias que se efetivam por meio de portarias e regulações de diferentes ordens ${ }^{3}$. Acredita que esta se apropria de temas da maior rele- vância como a reorganização da clínica, as relações de poder em serviços de saúde, gestão participativa e saúde do trabalhador da saúde. Busca, num processo de cogestão, construir formas de fazer política e administração, valendo-se de apoio institucional, difusão e debates de novos conceitos, partindo das experiências vividas no chão dos serviços de saúde, em sentido contrário à tradição verticalista e autoritária, muito comum no âmbito da saúde pública3.

$\mathrm{O}$ apoio institucional vem sendo praticado na PNH como método/dispositivo de intervenção em práticas de produção de saúde pública e, nesse sentido, propõe um "modo de fazer" mudanças necessárias para que o SUS se torne cada vez mais um exercício do comum, do público. A referida política busca ocupar e afirmar um lugar que aposta na criação de condições e possibilidades de construção de políticas públicas em saúde, portanto, interessa-nos mostrar nesse texto como o apoio institucional possibilita a criação dessas condições. Tomamos como matéria de análise desse método uma experiência em um grande hospital público no qual desenvolvemos a função "apoio" visando à construção de ações de valorização do trabalho e dos trabalhadores, e, à produção de saúde no trabalho.

Com essa prática procurou-se expressar os princípios do SUS em modos de operar nos diferentes equipamentos de saúde e propor a articulação das ações que se atualizam no cotidiano das unidades de saúde, propiciando, em/nas equipes, trocas solidárias e comprometidas com a dupla tarefa de produção de saúde e produção de sujeitos ${ }^{4-7}$. A proposta foi também de reafirmar e ampliar o exercício da descentralização e da autonomia da rede de serviços, de modo que esta passasse a funcionar como um canal de diálogo para a melhoria das condições de vida e saúde no trabalho. Entendendo que mudanças nos modos de fazer a gestão e atenção em saúde envolvem diretamente a maneira como os sujeitos compõem essa rede, ou seja, envolve os sujeitos em suas experiências concretas de relações cotidianas, afirmamos que as mudanças não se fazem sem um processo de produção de subjetividade que é sempre coletivo, histórico e determinado por múltiplos vetores: Vetores-dobras inseparáveis do campo da saúde: sujeitos (desejos, necessidades, interesses), processos de trabalho (saberes), poder (modos de estabelecer as relações) e políticas públicas (coletivização dessas relações).

É com esse entendimento que o método do apoio institucional busca fomentar nos atores que constroem essa rede o exercício pleno de suas 
condições, como: trabalhadores protagonistas de análises compartilhadas e intervenções nos seus espaços de trabalho. Lança-se no desafio de convocá-los no seu potencial de criação, próprio dos seres vivos, para configurar novos modos de gerir o trabalho, frequentemente marcado pela fragmentação e fragilização dos trabalhadores. Transformar o trabalho afirmando sua força de produzir o viver.

O sentido da prática do apoio institucional está no acompanhamento e na construção dos processos/percursos dessa transformação, colocando-se o apoiador "ao lado" dos sujeitos que vão experimentar/produzir as mudanças. Partindo da compreensão de que toda mudança nas práticas de saúde envolve análise dos processos de trabalho, o método do apoio propõe colocar em análise as formas como o trabalho vem sendo organizado, de modo autoritário em suas diversas maneiras de centralismos - por corporação, por modelo reduzido de saúde, por modelos verticais de gestão, por terceirizações, fomentando relações violentas no trabalho.

Quando nos referimos a modos de gestão, estamos falando das maneiras como se produzem realidades; de modos de se produzir no ambiente de trabalho, dos processos de coengendramento de sujeitos e mundos. Modos de gestão que perseguem processos de subjetivação como produção criadora. Modos de gestão, antes de tudo, como invenção de problemas que fazem ruir modos estabilizados de funcionamento; perturbação, rachadura do instituído. Uma organização do trabalho pautada prioritariamente por uma administração/gerência que não afirma os processos de gestão coparticipativos tende a produzir subjetividades metástases, ou seja, subjetividades amorfas, moldadas ao sabor dos interesses do capital e, portanto, com dificuldades de cultivar resistências às instituições, às técnicas de controle e à disciplinarização9

Nesse sentido, o apoio institucional é uma estratégia de fomento à gestão compartilhada dos processos de trabalho exercida nas práticas cotidianas concretas e que parte da premissa de que todo trabalhador é gestor de seu trabalho. É a cogestão tomada como método. Método que visa à colocação do apoiador ao lado dos sujeitos na análise de seus processos de trabalho, de modo a [não (inclui?)] deixar-se afetar nos coletivos por essas formas autoritárias de atenção e gestão, e procure instrumentos que provoquem desvios nelas, acolhendo e fortalecendo o que no grupo se desloca desses modelos. Esse é um método local e intensivista, um tipo de tecnologia relacio- nal que depende da análise do cotidiano dos processos de trabalho e de suas múltiplas implicações nos planos dos desejos, das relações e dos poderes. $\mathrm{O}$ apoiador trabalha com sujeitos coletivos e é dessa forma um fomentador da coletividade nos grupos que apóia. Nos modos verticais de organização do trabalho vemos os processos fragmentados e definidos autoritariamente para sujeitos que exercem as tarefas nos serviços. Aos modos fragmentados de organização do trabalho correspondem modos isolados de relações que, praticados em realidades complexas como a das diferentes práticas de produção de saúde, produzem efeitos desastrosos. No trabalho em saúde as redes de cuidado - coletivos de coletivos - são vitais, e a composição de grupalidades são condições importantes e muitas vezes ignoradas nos processos de produção de saúde pública. Seguindo os referenciais da Humanização/PNH, a grupalidade é uma experiência que não se reduz a um conjunto de indivíduos, tampouco pode ser tomada como uma unidade ou identidade imutável. É um coletivo ou uma multiplicidade de termos (usuários, trabalhadores, gestores, familiares etc.) em agenciamento e transformação, compondo uma rede de conexão na qual o processo de produção de saúde e de subjetividade se realiza.

Para o fomento da grupalidade e da gestão compartilhada é preciso haver deslocamento subjetivo dos atores envolvidos - que passam à condição de autores dos processos de trabalho e não meros executores -, o que, mesmo desejado por alguns gestores/gerentes, é impossível. De modo que a produção de saúde não se faz sem sujeitos capazes de se reposicionarem subjetivamente, de avaliarem que funções exercem, que lugares ocupam em seus processos cotidianos de trabalho e como podem transformar esses processos, o mundo e a si mesmos. Os trabalhadores nunca executam apenas as tarefas prescritas, sempre há criação, gestão das variabilidades, que é a condição para que os sistemas funcionem.

A maneira como queremos abordar o problema da subjetividade e os modos de produção da existência é pela afirmação de processos de subjetivação múltiplos, heterogenéticos e que podem resistir às diferentes tentativas de modulações que visam à homogeneização das formas de existência nos serviços. Conforme Rolnik, é preciso: ... criar alianças entre práticas que desertam ativamente a máquina de sobrecodificação $e$ inventam outras cenas, colocando em rede sua sinergia e ativando sua potência de singularização; inserir-se no movimento de reativação da força de 
invenção a contrapelo de seu esvaziamento vital, da neutralização de seu poder crítico ${ }^{10}$.

Os modos de gestão do trabalho engendram, portanto, muitas possibilidades de modos de subjetividade, outras possibilidades de subjetivação. Ao gerir seu trabalho, os humanos inventam formas de cooperação e uma certa relação a si, ou seja, num incessante processo de criação há sempre a possibilidade de diferir do que se cristalizou em nós.

No método do apoio institucional não é o apoiador quem produz a mudança ou é a causa da transformação. Ele trabalha com dispositivos que provocam a análise dos processos de trabalho (como acontecimentos do cotidiano, pesquisas, oficinas, matriciamentos, visitas institucionais, atividades de formação etc., praticados em rodas que favoreçam a circulação da palavra). Seguindo pistas da Análise Institucional Socioanalítica, são necessários analisadores que coloquem em cena a trama das relações entre desejos, saberes e poderes que permeia o trabalho. Um dispositivo trabalhado em roda dispara a análise dos processos, pois promove desvio das formas habituais de viver nos serviços. Ao disparar a análise, o dispositivo põe em cena sentidos dados e exercidos nas relações vividas nos processos de trabalho. Cabe à função-apoio acompanhar o processo disparado e construir uma atenção para os sentidos que expressam assujeitamento do grupo e para outros que fornecem caminhos de desvio, possibilidades de criação de novos modos de cuidar e de gerir o trabalho. Essas análises se tornam matéria para a construção dos planos de ação de mudanças de práticas que se orientam pela transformação do trabalho em saúde como forma do cuidador redirecionar o cuidado a si e se engajar na construção de novas práticas de cuidado. Cuidar-se (colocar coletivamente em análise os processos vividos cotidianamente) é condição para o cuidado coletivo. Gestão e atenção não se separam nessa perspectiva.

$\mathrm{O}$ apoio institucional lida ainda com a imprevisibilidade dos rumos que o processo irá tomar. A construção de dispositivos dispara e expõe muitas coisas, em especial as dinâmicas enferrujadas e/ou emperradas dos diferentes grupos institucionais, em especial as sustentadas pela concentração dos poderes/saberes em cargos e corporações. Dessa forma o método do apoio institucional é uma aposta e também possui uma duração. Sustenta-se de acordo com o desejo dos grupos em praticar a análise dos processos de trabalho em saúde e construir planos de intervenção nessa realidade, de modo a ampliar a di- mensão pública das práticas de produção de saúde no SUS. Ou, ainda, sustenta-se até que esse exercício seja incorporado pelo grupo e a função do apoiador se torne dispensável.

\section{$\mathrm{O}$ apoio institucional praticado pela Política Nacional de Humanização}

Seguindo seu projeto de ampliar a agenda para a política de saúde ${ }^{3}$, a PNH vem praticando o apoio institucional como método de trabalho em saúde que privilegia a cogestão, fazendo conexão com a força dos coletivos nas práticas nos serviços. Como política pública, entende que o SUS é uma política aberta, em construção cotidiana pelos seus autores/atores. Com esse propósito, por meio do apoio institucional, tem criado alguns dispositivos, dentre eles destacamos, para os fins desse texto, as rodas de conversa, o PFST (Programa de Formação em Saúde do Trabalhador) e a CAP (Comunidade Ampliada de Pesquisa). Comunidades Ampliadas de Pesquisa é uma expressão cunhada por pesquisadores brasileiros a partir do conceito de Comunidades Científicas Alargadas, produzido por Ivar Oddone, na década de 1980, no âmbito do Movimento Operário Italiano. Refere-se a uma estratégia de nucleação dos trabalhadores para análise do seu trabalho, partindo do princípio da não hierarquização de saberes.

Os dispositivos não são constituídos, portanto, de formas prescritivas de funcionamento, mas são construídos a partir das experiências singulares de cada unidade de saúde, abrindo-se para a análise dos processos de trabalho em curso.

Ao longo de sua constituição, o SUS tem enfrentado inúmeros desafios, uma vez que, como nos aponta Campos "(os trabalhadores) em saúde lidam com o limite humano, com nossa impotência, com a evidência de que não somos deuses". [...] Lidam com a morte, a doença e a dor. Trabalham em ambientes perigosos (germes, fracassos, competição etc.), logo, precisam, além de planos de carreira e salários, de Apoio ${ }^{6}$, o que no entendimento desse autor tem o sentido de "estar sempre em análise" ${ }^{6}$. A estratégia de apoio institucional praticado pela $\mathrm{PNH}$, tomada como método de intervenção, se expressa por uma função de apoio que dá passagem, persegue a criação de grupalidade, de forma a fortalecer e montar redes de coletivos. Lugar-função que instiga, lugar de passagem que viabiliza processos de desestabilização do que está instituído, fazendo emergir modos outros de trabalhar e produzir saúde; que 
faz surgirem outros planos de afetos, de encontros, de constituição de redes de conversa, redes afetivas.

Assim, o lugar-função do apoiador institucional, transborda os limites de todas as denominações sugeridas pela Teoria Geral de Administração para papéis semelhantes ${ }^{6}$. Trata-se de uma relação dinâmica que se estabelece entre o apoiador institucional e a equipe apoiada: nem uma postura de passividade ou omissão (dos apoiadores), nem a pretensão de operar à revelia dos grupos e de apenas elaborar pareceres, planos ou protocolos e normas às equipes. Segundo o autor, esse apoio à cogestão objetiva afirmar e incentivar a produção de coletivos organizados e ajuda a articular a produção de serviços, de instituições e dos próprios sujeitos. Campos ${ }^{6}$ indica a função do apoiador institucional como aquele que ajuda na gestão e na organização de processos de trabalho, na construção de espaços coletivos nos quais os grupos analisam, definem tarefas e elaboram projetos de intervenção. O apoiador institucional compromete-se com as equipes a quem deve comunicar suas avaliações e suas análises. Nesse sentido, contribui para a efetivação dos processos de cogestão no trabalho, devendo principiar com a construção de um contrato que estabelece expectativas, objetivos, regras, métodos e o que mais surgir durante o processo.

Apoio, portanto, que envolve a discussão/ problematização dos modos como a gestão nas relações de trabalho se expressa, de forma que a produção da saúde implica na produção dos sujeitos que a produzem. Logo, no trabalho de apoio institucional construído na $\mathrm{PNH}$ visa-se a produção de uma ética que afirma modos singulares de se trabalhar em saúde e de produzir o viver, que ganham força a partir da força que viabilizamos ao outro afirmar.

Por conseguinte, esse trabalho de apoio se constitui a partir de um pressuposto essencial: a recusa de qualquer forma de tutela. Recusa dos especialismos, colocando em análise um mandato social, ou seja, o ininterrupto pedido de intervenção feito aos intelectuais, que instaura a divisão de saberes em especialidades ou disciplinas ${ }^{11}$. Fazer com os trabalhadores e jamais por eles, ou seja, a equipe externa ao serviço que propõe o apoio não pode se tornar elemento imprescindível no processo de análise das situações cotidianas, na construção de outros modos de fazer a gestão dos estabelecimentos. O que se espera e se almeja é que o trabalhador, ao ser quebrada qualquer relação de dependência e/ou tutela, se aproprie do seu fazer. Privilegiam-se as demandas e os conhecimentos advindos da experiência dos trabalhadores, considerando-se sua participação como fecunda e indispensável.

Esse processo torna-se possível por meio da cooperação que viabiliza a construção e a transformação, no coletivo, das regras do trabalho. É preciso correr o risco de se envolver num debate coletivo, quando cada um mostra como trabalha, e, ao mostrar, dá visibilidade também ao seu não saber, uma vez que não se sabe tudo nem isso é desejado.

Sofrimento, resistência, obstinação e situações de fracasso fazem parte do trabalho. Trabalho é aspecto central para a produção de subjetividade, pois o sujeito se transforma com o trabalho. Trabalhar é poder se transformar. Comentar, falar, defender seu trabalho é fundamental para que a cooperação possa existir. A capacidade de falar e de escutar é necessária para a cooperação e pressupõe riscos.

O trabalho implica, necessariamente, uma relação com alguém; é cooperação que pressupõe um coletivo e é conflituosa, pois a capacidade de entrar em conflito é a base da cooperação. Os indivíduos se mobilizam para cooperar e esperam retribuições, como, por exemplo, o salário, mas também o reconhecimento, o olhar do outro. Não se trabalha só por dinheiro. Os métodos de trabalho falam de um patrimônio histórico construído pelos humanos no curso das suas atividades, logo, não são naturais e muito menos completos. Por conseguinte, carregam um rico potencial de transformação. Falamos, portanto, do limite das formas e da riqueza das forças vivas que constituem os serviços, como fonte inesgotável de criação de outras formas de fazer saúde, outras formas de trabalho.

As regras do trabalho não são apenas técnicas, específicas de um campo profissional, mas, principalmente, saber como é possível trabalhar junto, afirmando a autonomia de cada um no trabalho, o que não significa qualquer espécie de individualismo. Trata-se de uma regra ética e técnica, pois os mundos do trabalho são mundos do conviver. Trabalhar não é apenas poder agir, mas conviver, estar junto. Então, como saber sobre o trabalho a não ser falando sobre ele, construindo o saber/fazer coletivo, construindo espaços de deliberação?

Não há nenhum tipo de privilégio de um saber sobre o outro. A questão é avaliar os ecos e a ressonância entre eles. Relações de ressonância mútua e de troca. Linhas que não cessam de interferir entre si. Saberes da experiência, saberes acadêmicos. Saberes que se misturam e que vão 
compondo outros mundos, outros sujeitos, outros trabalhos. O apoio institucional a uma zona imprecisa, instigando forças que podem gerar outras formas, outros modos de produzir saúde.

Diante disso, perguntaríamos: Que práticas têm sido engendradas nos estabelecimentos de saúde? Como instituir processos de trabalho nos serviços, tendo como direção a cogestão? Como nos diz Benevides:

Construir espaços democráticos de compartilhamento de saber-poder, tornar inseparável a atividade da gestão da atividade, aumentar o grau de transversalidade nas redes de trocas afetivocomunicacionais entre os grupos são modos de enfrentar a lógica de funcionamento instituído ${ }^{12}$.

Foi nessa direção ético-política, exercendo a função de "apoiadoras institucionais", que construímos algumas estratégias de trabalho, a partir do método de apoio institucional, num Hospital Geral do Rio de Janeiro e que passaremos a relatar.

\section{Do apoio institucional: uma experiência em um Hospital Geral}

As ações de apoio desenvolvidas num Hospital Geral, na cidade do Rio de Janeiro, em parceria com a PNH, tiveram início em 2005 e, até hoje, acompanhamos grupos de trabalhadores nesse hospital. Um apoio intensivo de acompanhamento, interferência e intervenção nos processos em curso. $\mathrm{O}$ apoio tem se efetivado como um modo de operar pautado na construção permanente de parcerias e encontros entre diferentes atores que constroem o cotidiano do hospital, a partir das condições reais que se apresentam na unidade de saúde em pauta. As ações são ancoradas no concreto das experiências que ali têm lugar, sempre considerando suas especificidades loco-regionais. Visa-se ao acompanhamento qualificado, que se configurou como ações de matriciamento do trabalho de duas equipes: uma que se constituiu como comitê para implantar o Acolhimento na emergência do hospital e outro para a instituição de um serviço de saúde do trabalhador. Foram ofertadas algumas contribuições metodológicas para as propostas formuladas, ainda de forma inicial por esses dois grupos. A convocação é para a construção de redes pactuadas por todos aqueles que constituem o referido hospital (gestores, profissionais de saúde e usuários), apostando e afirmando a importância da instituição de rodas de discussão e trocas multiprofissionais.

A constituição de um grupo de trabalhadores para a análise dos processos de trabalho e saúde no hospital organizou-se há dois anos, após a construção coletiva entre os apoiadores da PNH e os trabalhadores de um Programa de Formação em Saúde do Trabalhador (PFST) ${ }^{13}$. Como desdobramento dessas primeiras ações, constituiu-se uma Comunidade Ampliada de Pesquisa (CAP) no setor da Emergência, a partir de uma pesquisa sobre a situação de trabalho no setor. A pesquisa abordou questões como dinâmica das relações interpesssoais/institucionais, o espaço de trabalho no setor de emergência, os sinais de adoecimento e suas formas de enfrentamento neste setor, tendo seus resultados sido divulgados para trabalhadores e gestores do hospital ${ }^{13}$.

Esse processo, que tem contado com apoio institucional, teve como desdobramento a formação de um Comitê de Saúde do Trabalhador do Hospital, com a função de construir um Serviço de Saúde do Trabalhador que propusesse alternativas para uma efetiva transformação das condições e organização do trabalho no estabelecimento. Depois de algumas ações de apoio ao referido comitê, que incluíram reuniões com a direção do hospital, conversas com os participantes, oficinas para debates sobre conceitos e metodologias no âmbito do nomeado campo da saúde do trabalhador, o comitê foi oficialmente instituído com publicação em Diário Oficial.

Acompanhando o desdobramento da constituição de um comitê, podemos ver a formação de um grupo que se organizou para análise das condições de trabalho e saúde na instituição.

\section{Efeito-intervenção do método do apoio institucional}

Ao longo dos últimos anos o comitê encontrou um cenário ainda frágil no âmbito das políticas governamentais no que diz respeito à saúde do servidor público. Nesse âmbito, os recursos são limitados, ou então, há órgãos com serviços bem estruturados, mas ociosos, que não desenvolvem políticas sólidas no campo da saúde do servidor e, portanto, fora de sintonia com a longa história de luta dos trabalhadores por melhores condições de trabalho. Outro aspecto que merece destaque é o fato de que nos últimos anos o investimento na área de saúde do servidor público dependeu do entendimento individual de cada gestor. Não existe, por exemplo, qualquer tipo de relação estruturada com outros órgãos de modo a firmar acordos mútuos de cooperação. O hospital em questão, durante toda sua existência, nunca realizou ações de promoção; faz 
ações pontuais, descontínuas e desarticuladas dos processos de trabalho em curso. A direção se diz favorável à implantação de uma comissão de saúde para os trabalhadores, mas as ações efetivas de apoio no que diz respeito aos encaminhamentos necessários para a instituição desse serviço no hospital são ainda muito frágeis. Não existe nenhum sistema de informações, de notificação dos agravos à saúde dos servidores, o que vem dificultando bastante algumas ações e o real entendimento das questões relacionadas à saúde dos trabalhadores.

O comitê fez esforços para construir um diagnóstico e uma avaliação dos recursos físicos, materiais e humanos existentes no hospital; buscaram, com muita dificuldade, construir uma Política de Promoção e Vigilância à Saúde, identificando problemas e potencialidades, de forma a gerar informações essenciais para apoiar a organização dos diferentes setores do hospital e a implementação das políticas de promoção e vigilância. Ações que objetivaram intervir no processo de adoecimento, sem reduzi-lo a seus aspectos individuais, mas entendido como articulado às relações coletivas travadas no ambiente de trabalho. Essas ações perseguiram mudanças na organização do trabalho, buscaram movimentos de resistência ao que adoece e enfraquece a força do viver e priorizaram também a formação dos trabalhadores para a adoção de práticas que melhorem a qualidade de vida/trabalho. Diferentes trabalhadores se engajaram nesse processo.

Verificamos que as ações desse grupo não conseguiram transformar práticas, apoderar-se da gestão do cotidiano de seu próprio trabalho. Era preciso colocar os processos de trabalho do grupo e a função apoio em análise. A opção feita foi, então, colocar em análise o que vinham fazendo e como, discutir a grupalidade em oficinas, e a própria função do apoio. Análise proposta como exercício do pensar juntos os processos de trabalho no hospital e no comitê em suas naturalizações, cristalizações, mas também para a riqueza de possibilidades e potencialidades. Nosso objetivo era fomentar a produção de estratégias de transformação que deixassem de ser tomadas como tecnicismos estéreis e que funcionassem como reencantamento nas práticas cotidianas.

Decidimos, então, acompanhar as reuniões quinzenais do Comitê de Saúde do Trabalhador, ocorridas no hospital, de forma a produzir deslocamento no modo burocratizado que, muitas vezes, bloqueia o movimento do grupo, produzindo um baixíssimo grau de resolutividade e transversalidade. Como se opera tamanha redução dos modos de funcionamento? Perguntávamos-nos inicialmente.

Coordenação sem liderança, baixo grau de transversalidade no grupo, dificuldade de quebrar alguns hábitos cristalizados. O processo grupal marcado, muitas vezes, por um funcionamento queixoso e ressentido. Interesses pessoais sendo privilegiados, culpabilizações individuais pela inoperância e dificuldades enfrentadas. Ações que privilegiam vantagens pessoais e autoritarismo da coordenação que se expressa tanto pelo descaso quanto pelo enaltecimento das impossibilidades e deficiências do grupo. Práticas que procuram responsabilizar outras esferas do hospital ou do Ministério da Saúde pela difícil movimentação do grupo. Muitas vezes as análises eram paralisadas diante das divergências de concepções sobre o que seria um serviço de Saúde do Trabalhador. O que queremos, afinal? Não estamos reeditando um serviço de saúde ocupacional pouco transformador dos processos de trabalho que produzem adoecimento e que tanto criticamos? O grupo muitas vezes se depara com sua morte. Conseguiremos realizar nossas metas? Até quando ficaremos definindo o modo de funcionamento do grupo? Quando vamos nos abrir para que outros companheiros entrem no nosso grupo? Essas e muitas outras questões acompanham o grupo no seu processo de fundação.

A cada intervenção outras falas encontravam espaço de dizibilidade. Expressavam um modo de experiência da dinâmica grupal que demandava transformação: "nós somos um grupo adoecido", "é um grupo dividido", "nosso coordenador é ausente", "não temos coordenação", "não terminamos os projetos que construímos". O que se passa no grupo? Como fortalecer o diálogo para que outros modos de trabalhar se instituam?

Rodas de conversa. Diálogos que fazem a roda girar. Produção de grupo-sujeito. Como nos indica Bakthin ${ }^{14}$, os humanos se constituem logo que o diálogo começa e a última palavra não é jamais dita. O diálogo que não é um resultado de um ato deliberado de abertura ao outro, mas resulta, ao contrário, da impossibilidade de se fechar à alteridade ${ }^{14}$.

Em meio a queixas, lamentos e falas de impossibilidades por meio de relatos daquilo que o grupo não foi capaz de fazer, nos situamos no movimento produzido no grupo, tentando ser aceito por ele, buscando desbloquear os movimentos de invenção do viver. Os desafios são inúmeros. As questões insistem: Como fomentar o diálogo? Como enfrentar os sentimentos de im- 
potência e inoperância expressa nas falas dos trabalhadores? Função apoio habitando essa zona imprecisa, dando passagem a novas formas de expressão, novas linguagens. Função apoio que se abre para as forças criativas.

O que dizem, então, os trabalhadores? "O apoio contribui em orientação, produzindo discussão, trazendo elementos técnicos e até bibliográficos que orientam o grupo. Uma outra coisa é o olhar de fora que é meio de dentro, a consultoria é de fora, mas é de dentro do Ministério da Saúde, dentro do processo do hospital, fica fora e olha com um olhar que ajuda a gente a tirar os vícios das nossas lentes mal acostumadas dentro do hospital." Outro membro do comitê diz: "A gente tem conseguido colocar em prática muitas coisas que na discussão só ficavam no papel, e torná-las reais, não só virtuais. Nós tivemos o nosso evento, a oficina, vamos começar a aplicar a pesquisa... Nós estamos começando a caminhar melhor".

Deriva em relação aos territórios instalados. É necessário emigrar dos territórios estabelecidos para poder criar outros modos de viver, produzindo o viver. Como destruir os atuais territórios habitados pelo grupo sem que este desmorone?

$\mathrm{O}$ apoio se oferece, ao mesmo tempo, como dispositivo de intervenção (produção de transformação e produção de conhecimento), mas, também, como oportunidade para construção do plano que queremos acessar nas intervenções e conhecer: plano político e subjetivo, plano coletivo. Os modos de funcionamento do comitê, aparentemente imóveis e intocáveis, movimentam-se imperceptivelmente, assumindo uma forma sempre arriscada a sucumbir ou transformar-se frente à força da próxima onda.

É preciso recusar posturas pautadas prioritariamente pelas críticas à direção do hospital ou aos demais âmbitos do Ministério da Saúde, dizendo que nada teriam a ver com o que ali se passa. Contrapormos-nos, confrontar, lutar por sua transformação a partir dos movimentos, propor saídas, ensaiar essas saídas, e se deparar, muitas vezes, com a dificuldade ou com a impossibilidade de consegui-las. Considerar que as dificuldades encontradas são movimentos que podem fortalecer o grupo. Quem faz aquele hospital, ou seja, quem estabelece determinados padrões de exigência e modos de nele trabalhar são os próprios profissionais que, em seguida, queixam-se do hospital que lhes impõem normas e valores, numa posição de alheamento e desresponsabilização do que ali acontece.

O que estamos afirmando é que a vida no hospital é feita por todos aqueles que habitam o serviço de saúde. Se almejamos ampliar as possibilidades de construção de um Serviço de Saúde do Trabalhador naquele hospital e sair de uma posição passiva e corporativa de quem fica esperando que as mudanças aconteçam, é preciso lançarmo-nos na tarefa de colocar em análise tal funcionamento produzindo protagonismo e corresponsabilidade. Como aquele grupo suporta o teste da potência de vida? Seria esta a experiência de grupo que queremos produzir? Seria, então, esse grupo um terrível espelho de nossos modos de existência, do qual não podemos nos livrar?

Nas reuniões, cada participante versava sobre seus interesses dentro daquele grupo: a obrigatoriedade de exames periódicos, a aplicação de um questionário sobre doenças ocupacionais, a elaboração do projeto para o Comitê tornar-se um Serviço de Saúde do Trabalhador, entremeados a lamentos, às incapacidades e aos problemas relacionais. Enfim, em meio a tudo isso, a dificuldade de construir um comum, produção de um coletivo de trabalho, construção de regras. Dificuldade de construção de um espaço público, espaço de fala, que produz cooperação e constrói coletivos de regras. Buscar caminhos para a cooperação que constrói um produto comum a partir da solidariedade. Ações coletivas que construam as bases da cooperação para que se efetive uma política pública.

Após dois anos de existência oficial do Comitê, ele não foi legitimado pelos demais trabalhadores do hospital. As ações de interferência ou modificação dos processos de trabalho são inexistentes. Muitas ações são levadas a cabo de forma isolada por alguns dos participantes que se empenham para que o grupo não se dissipe. Insistem e acreditam na possibilidade de colaborar com os trabalhadores de saúde e com as modificações das organizações de trabalho da instituição. Foi pegando carona nesse movimento que construímos, junto ao Comitê, estratégias para que, com eles, pudéssemos superar os desafios experimentados ao longo de sua existência.

A primeira ação construída foi a organização de um evento que apresentasse o Comitê de Saúde do Trabalhador e suas linhas de ação para os demais trabalhadores do hospital. Tal estratégia, e a própria preparação do evento, permitiu a entrada de outros trabalhadores de saúde no Comitê, reconfigurando a dinâmica grupal estabelecida até então.

Em meio a idas e vindas, víamos que a construção de um "comum" é tarefa árdua, e nosso apoio se efetivou no sentindo de fazer com que o grupo, ao colocar em análise seu próprio pro- 
cesso de trabalho, pudesse construir outros atalhos. Como imprimir outro ritmo ao trabalho? Como criar outras gingas, outras cadências?

O evento de apresentação oficial do Comitê de Saúde do Trabalhador aconteceu com uma grande mobilização dos trabalhadores. O diretor do hospital e outros chefes de serviços participaram do evento. Alguns trabalhadores, ao fazerem pronunciamentos quanto ao sofrimento e ao adoecimento causados pelos processos de trabalho, afirmaram seus compromissos com o Comitê no sentido de lutar por mudanças das condições experimentadas. Assim, alguns passos foram dados na direção de uma legitimação do trabalho realizado.

O que podemos avaliar é que o encontro produziu, em um grupo fragmentado e enfraquecido, um efeito de protagonismo e de força de transformação de práticas verticalizadas. Evento esse que possibilitou a construção de atalhos, de outros percursos, de outras gingas embaladas por essa nova configuração e outras ações foram promovidas, como a realização de uma oficina com a temática de grupalidade e normas para a implantação de um serviço de saúde do trabalhador. As oficinas objetivam um processo de formação que, mais do que informar os trabalhadores sobre algumas matérias e regulamentos importantes para a instituição, visa à produção de outros sujeitos e modos de trabalhar.

A oficina realizada contou com a presença de um grupo diversificado de trabalhadores, alguns que já frequentavam os encontros do Comitê e outros que se interessavam pelas questões da saúde do trabalhador. Debatemos o sentido de grupo, e os participantes apontaram a construção de um comum como ponto importante da grupalidade, abordou-se, também, a idéia de que é a partir da construção efetiva de um grupo (colaborativo, solidário, responsável e resolutivo) que um serviço de saúde do trabalhador pode ser viabilizado. Nesse momento, o Comitê se encontra com sua própria contradição: esse grupo possui essas características que pensamos como necessárias à efetivação da política que ele propõe? Provocados por essa contradição, os profissionais lançaram luz mais uma vez às questões do próprio grupo, como a necessidade de uma nova configuração. Essa nova configuração já estava em processo de produção e poderia ser legitimada através de mudanças. Uma mudança significativa já estava a caminho: mostrava-se necessário novo acordo dos membros do grupo que agora se ampliara quanto à coordenação. Esta coordenação cumprira já dois anos. Os par- ticipantes avaliaram que a oficina foi proveitosa. Esperávamos seus efeitos.

O encontro seguinte com o Comitê foi impactante. As forças dos interesses privados, dos territórios cristalizados e do autoritarismo, muito marcantes na fala da coordenação que não estivera presente na oficina, ressoaram, surgiram como reação e como tentativa de negação dos processos de mudança em curso. A gestão participativa do grupo mostrava-se como um grande desafio. O grupo mais uma vez sucumbia a essas forças e apresentava-se oprimido, desvitalizado, sem autonomia e assujeitado. A coordenação questionava a presença da $\mathrm{PNH}$ junto àquele Comitê. Como sustentar a função de apoio institucional diante dessa circunstância?

Preparados para retomar e pôr em análise a função do apoio da PNH ao Comitê, fomos ao próximo encontro com o grupo. Antes mesmo do início, alguns trabalhadores sugeriram que não se tocasse nesse assunto, pois a coordenação (mais uma vez) não estaria presente, e poderíamos provocar nova reação. O encontro voltou ao seu tom habitual: a insistência em pensar os exames periódicos (sem articulação com os processos de trabalhos), queixas, alguns participantes dormiam e discutia-se burocraticamente sobre o questionário. Lembramos da necessidade de abordar o apoio da PNH e marcamos nova reunião com a presença da coordenação.

Esse último encontro nos provocou a análise da função que o apoio institucional vem exercendo. Pensamos que essa função acompanha os preceitos do modo de fazer da $\mathrm{PNH}$ que aposta no método da tríplice inclusão e, portanto, inclusão também dos conflitos. Sobre a questão da humanização, a articulação entre o 'que fazer' e o 'como fazer' é uma questão relevante ${ }^{2}$. Seguindo princípios e diretrizes que são também do SUS, essa política pública de saúde pretende se efetivar principalmente pelo modo de fazer que propõe. Um método que vai sendo construído durante o caminho e que envolve a inclusão de pelo menos três vetores do cuidado: dos sujeitos (gestores, trabalhadores, usuários), dos coletivos (movimento sociais e movimentos sensíveis) e dos analisadores sociais (aspectos que colocam nossa prática em análise, problematizando-a). Para garantir a primeira inclusão apostamos no "fazer roda”, numa prática de lateralização que garanta que a comunicação se ponha a rodar. $\mathrm{O}$ apoio institucional, por meio do aquecimento da roda (facilitando e provocando a comunicação em grupo) provoca uma desestabilização da forma tradicional como a comunicação vem se realizando. 
Em uma instituição podemos encontrar, comumente, dois eixos de organização da comunicação: a comunicação entre os diferentes na instituição - comunicação vertical, de obediência; e a comunicação entre os iguais - comunicação corporativa. Para uma aposta nas mudanças das práticas é necessário um terceiro eixo: o da transversalidade, eixo de uma comunicação lateralizada entre os diferentes setores e especialidades. $\mathrm{Ou}$ seja, o aumento do grau de abertura de comunicação nos grupos e entre os grupos. A transversalização nos modos de se comunicar só é possível se os lugares de saber-poder forem alterados. $\mathrm{Na}$ prática de confronto com a diversidade dos grupos há uma potência de diferenciação a partir das conexões entre uma multiplicidade de modos de ser e fazer, principalmente porque esse confronto faz emergir pontos críticos que podem ser analisadores institucionais que provocam a arguição crítica do instituído. O apoio, pela inclusão, revela os tensionamentos e propõe que estes sejam incluídos na roda de comunicação.

Essa é uma prática institucional que provoca a construção de um outro lugar para o grupo que não mais o de uma hierarquia vertical (que envolve disputas de poder e de autoridade) nem de uma corporação horizontal (que esteriliza as relações). O desafio colocado é a construção de um lugar de sustentação do desejo do grupo, dimensão esta que, afirma Guattari, é própria de certos grupos que ao assumirem o "sentido de sua práxis" podem instaurar-se como "gruposujeito". Com isso o grupo-sujeito é capaz de uma prática de marcação que envolve a inclusão de "crises capazes de pôr em causa o destino do grupo em contextos mitificados"15, ele assim se posiciona em relação a sua finitude. Em oposição relativa a esse grupo-sujeito, outros grupos são determinados pelo exterior e se mantêm assim de forma passiva. Por meio de "mecanismos de autoconservação se protegem de maneira mágica de um não-sentido considerado exterior; assim agindo, recusam toda possibilidade de enriquecimento dialético na alteridade do grupo"15.

O apoio institucional é, assim, um dispositivo que faz aparecer esse emaranhado de forças que sustentam os conflitos e ao mesmo tempo dispara processos de análise. Entendemos que faz parte do apoio a tarefa de dar emergência aos conflitos, e tal foi o efeito das oficinas e encontros realizados, que serviram de analisadores do funcionamento grupal. Colocaram em cena o estado fragilizado do grupo e a posição que o grupo vem colocando o apoio. Rejeitando a função deste como tutela ou como sustentação do grupo, pensamos que nesse momento o apoio institucional, para manter sua função/operação de análise e crítica das formas instituídas e centralizadoras dos/nos grupos, exige uma retirada, um recuo estratégico. Apostamos no recuo (que não é abandono) do apoio para que o grupo possa se ver e a seus problemas e, então, possa reconfigurar uma demanda endereçada à $\mathrm{PNH}$, na qual o desejo do grupo possa aparecer com mais força. Recuo que pretende favorecer ao grupo a experiência da sua própria finitude, condição para tornar-se um grupo sujeito, grupo que tenta assumir o sentido de sua práxis.

\section{Algumas reflexões finais}

A conclusão que podemos parcialmente propor para esse texto envolve uma torcida pelos efeitos da análise do grupo. Esperamos, como apoiadoras, que a grupalidade se fortaleça no Comitê, mas isso não nos faz deixar de observar os desafios enfrentados nas práticas cotidianas do trabalho em saúde. Em primeiro lugar, o não envolvimento dos sujeitos ocupantes dos cargos de gestão nos processos de mudança empreendidos por trabalhadores que não pertencem a esses cargos compromete a cogestão dos processos de trabalho em saúde. Concluímos, ainda, que a dimensão das relações entre sujeito individuais e coletivos que se fazem presentes de forma crucial e complexa nas diferentes instâncias das práticas de produção de saúde vem sendo ignorada nas diferentes práticas e pesquisas em saúde, e que o exercício da gestão compartilhada, da descentralização, da cogestão (a dimensão pública) da rede SUS mantém-se, também, por esse motivo, como promessa não concretizada. $\mathrm{O}$ apoio institucional é praticado pela/na PNH como método de intervenção para a promoção da dimensão pública do SUS, que não pode garantir essa transformação almejada, principalmente sem o envolvimento dos sujeitos atuantes nos cargos de gestão em saúde, mas que, no entanto, se afirma como tecnologia relacional partindo da premissa de que a produção de saúde não se faz sem a produção de sujeitos corresponsáveis e autônomos nesse processo. As tramas de relações entre os modelos autoritários de gestão do trabalho e as possibilidades de autonomia e protagonismo nesses processos é a matéria de trabalho do método do apoio institucional. Este método propõe aos apoiadores estarem no corpo a corpo desses embates, ao lado dos sujeitos coletivos, procurando fomentar condições nem sempre 
imediatamente possíveis, de intervenção e transformação das práticas autoritárias nas relações do trabalho em saúde. É importante, ainda, concluir que esse método coloca sua própria função em análise, pois corre risco todo o tempo de ser cooptado pelo autoritarismo, pelo centralismo do poder em instrumentos burocráticos de saber-poder, e ter de questionar essa função em sua duração e finitude.

Os efeitos produzidos indicam que o método é uma estratégia potente para a intervenção dos processos de trabalho no âmbito das políticas públicas de saúde, uma vez que envolve e traz à cena a dimensão das relações (de saberes desejos e poderes) entre os diferentes sujeitos. Encontrar desafios e ter de lidar com a finitude dos modelos instituídos não aponta uma falência do método, mas sua própria função sendo posta em operação. Condição para a construção de novas práticas. É importante assinalar, ainda, que o apoiador persegue uma postura ética que é a de aliar-se com práticas que efetivamente promovam uma transformação nos graus de autonomia e coletividade no âmbito das políticas públicas de saúde, e, ao mesmo tempo, é a de procurar coletivamente resistir — imprimir resistência ativa - aos processos autoritários de gestão e degradados da atenção/cuidado no SUS.

\section{Colaboradores}

MEB Barros, MMR Roza e CR Guedes participaram igualmente de todas as etapas de elaboração do artigo. 


\section{Referências}

1. Associação Brasileira de Pós-Graduação em Saúde Coletiva (Abrasco). Informativo da Associação Brasileira de Pós-Graduação em Saúde Coletiva. Rio de Janeiro: Editorial Abrasco; 2005.

2. Benevides R, Passos E. A humanização como dimensão pública das políticas de saúde. Cien Saude Colet 2005; 10(3):561-571.

3. Campos GWS. Prefácio. In: Santos-Filho SB, Barros MEB, organizadores. Trabalhador da saúde: muito prazer - Protagonismo do trabalhador na gestão do trabalho em saúde. Ijuí: Unijuí; 2007. p. 11.

4. Campos GWS. Subjetividade e administração de pessoal: considerações sobre modos de gerenciar o trabalho em equipes e saúde. In: Merhy EE, Onocko $\mathrm{R}$, organizadores. Agir em saúde: um desafio para o público. São Paulo: Hucitec; 1997. p. 229-266.

5. Campos GWS. O Anti-Taylor: sobre a invenção de um método para co-governar instituições de saúde produzindo liberdade e compromisso. Cad Saude Publica 1998; 14(4):863-870.

6. Campos GWS. Saúde Paidéia. São Paulo: Hucitec; 2003.

7. Campos GWS. Clínica e Saúde Coletiva compartilhadas: teoria Paidéia e reformulação ampliada do trabalho em saúde. In: Campos GWS, Minayo MCS, Akerman M, Drumond Júnior M, Carvalho YM. Tratado de Saúde Coletiva. São Paulo, Rio de Janeiro: Hucitec, Fiocruz; 2006. p. 53-92.

8. Barros MEB, Benevides R. Da dor ao prazer no trabalho, In: Santos-Filho SB, Barros MEB, organizadores. Trabalhador da saúde: muito prazer - Protagonismo do trabalhador na gestão do trabalho em saúde. Ijuí: Unijuí; 2007. p. 62.

9. Neves CEAB. Sociedade de controle, o neoliberalismo e os efeitos de subjetivação. Revista Saúde e Loucura 1997; 6:75-98.
10. Rolnik S. A vida na berlinda. Revista Trópico [periódico na internet]. 2002 [acessado 2011 out 10]: [cerca de 3 p.]. Disponível em: http://pphp.uol. com.br/ tropico/html/textos/1338,1.shl

11. Lourau R. Les Lapsus des intellectuels. Paris: Privat; 1981.

12. Benevides R. Prefácio. In: Santos-Filho SB, Barros MEB, organizadores. Trabalhador da saúde: muito prazer - Protagonismo do trabalhador na gestão do trabalho em saúde. Ijuí: Unijuí; 2007.

13. Barros MEB, Bastos SS, Zandonai AP, Vieira LFD, Bergamim MP, Scarelli RS. A experiência do programa de Formação em Saúde e Trabalho em um hospital público com serviço de urgência. In: Santos-Filho SB, Barros MEB, organizadores. Trabalhador da Saúde: muito prazer - Protagonismo do trabalhador na gestão do trabalho em saúde. Ijuí: Unijuí; 2007.

14. Clot Y. L'auto-confrontation croisée en analyse du travail: l'apport de la théori bakhtinienne du dialogue. In: Filliettaz L, Bronckart JP, organizadores. L'analyse des actions et des discours en situation de travail. Paris: De Boeck. sous presse.

15. Guattari F. Psicanálise e Transversalidade: ensaio de análise institucional. São Paulo: Idéias \& Letras; 2004.

Artigo apresentado em 19/06/2009

Aprovado em 23/01/2010

Versão final apresentada em 05/02/2010 